\title{
Regional Food Price Inflation Transmission
}

\author{
Franck Cachia
}

Food and Agriculture Organization of the United Nations, Statistics Division, Italy

Copyright $\subseteq 2017$ by authors, all rights reserved. Authors agree that this article remains permanently open access under the terms of the Creative Commons Attribution License 4.0 International License

\begin{abstract}
Understanding to what extent and speed agricultural commodity price changes on international markets are transmitted to consumers is key in assessing the vulnerability of households to price shocks. The importance of these transmission indicators is compounded, in developing countries, by the fact that consumers tend to spend a higher proportion of their income on food items. Regional estimates of food inflation transmission can also be used to predict consumer-level impacts of international price shocks, contributing to improve the information basis on which to base policy mitigation actions and to focus on the areas likely to suffer the most. The aim of this paper is to provide estimates of the transmission of price changes from international commodity markets to consumers in different regions of the world, using monthly data from FAO's Food Price Indices and Regional Food Consumer Price Indices. This econometric analysis, which uses impulse response functions from error-correction models, is useful in establishing typologies of regions with respect to the extent and speed of price transmission processes.
\end{abstract}

Keywords Food Price Inflation Transmission, Regional Food Consumer Prices, Error-correction Models

JEL codes: C32, Q11

\section{Introduction}

This paper provides statistical evidence on the extent and speed of the transmission to consumers of price fluctuations occurring on international food commodity markets, for a set of regions of the world. On the basis of these estimates, the regions and sub-regions most exposed to international shocks are identified and indications on the driving factors explaining cross-regional differences, such as market structures or policy mitigation measures, are also provided.

This analysis is useful in many regards: first, to our knowledge, consistent and up-to- date measures of food inflation transmission at regional level do not exist in the literature; second, the determination of a typology of regions with respect to their exposure to shocks on international food commodity markets contributes to better inform the design of food security policies; third, the estimated functional relationships linking food consumer prices to international commodity prices can be used to produce forecasts that can feed into early warning systems for food security.

The remaining sections of this paper are organized as follows: the second section describes the major determinants of food price transmission; the third section presents a range of econometric models that can be used to estimate food price transmission and the approach adopted in this paper. The fourth section presents the results of the estimations for selected regions and the factors explaining regional differences; the fifth and final section concludes and identifies possible improvements to the methodology. Annexes provide details on the data used and on the results of the transmission estimations and regressions.

\section{Determinants of Food Price Transmission}

For this study, food price transmission is defined as the percentage change in food consumer prices resulting from a given change in the international market price of a basket of agricultural commodities. We propose here to directly measure the impacts of price shocks at the upstream or producer level on downstream consumer prices. These impacts are the result of a complex chain of factors, with both amplifying and mitigating effects, occurring at different levels of the value-chain. A succinct description of the main determinants is provided in this section.

\subsection{Commodity Imports}

International food prices are first related to domestic food prices through commodity imports: directly, through purchases of goods from wholesalers on international output markets and indirectly, through purchases of agricultural inputs from producers on international markets (seed, feed, raw commodities, etc.), which affect production costs (Figure 1). In principle, the higher the share of commodity imports in domestic supply, the higher the correlation between international market prices and domestic prices. 


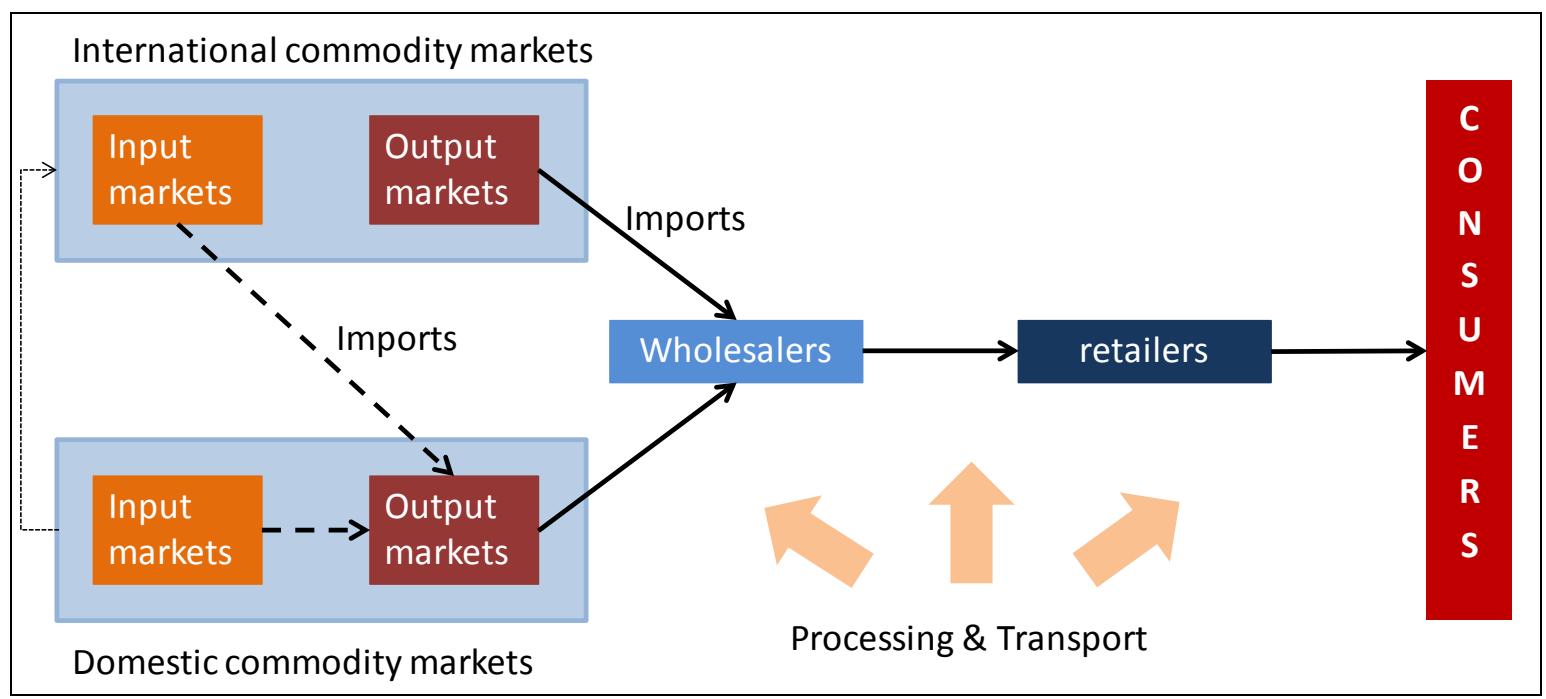

Source: Author

Figure 1. Transmission of shocks to domestic consumers

\subsection{Spatial Arbitrage and the "Law of One Price"}

When producers can arbitrate freely between selling their products on the domestic market or abroad, domestic producer prices and international market prices will tend to converge: domestic producers will sell their products abroad if the international price (net of transport and transaction costs) is higher than the domestic price, reducing the supply on the domestic market and therefore generating upward pressures on domestic prices. This process will continue until domestic producer prices are equal to international prices. This model, sometimes referred to as the "law of one price" is valid for homogeneous commodities traded in markets undistorted by export restrictions, trade barriers or price support policies and which benefit from perfect information (efficient markets). Ninot (2010) describes in detail the theoretical framework underpinning this approach. Rapsomanikis et al. (2003) also recall the "law of one price", in its weak and strong form, and identify its main implications for time-series modeling. The law of one price explains why prices tend to move in similar directions, especially when price changes on international markets reach certain thresholds. It may also explain the existence of a significant correlation between domestic and international prices in a country or region which is little dependent on food imports.

\subsection{Market Power}

The extent to which shocks on international markets are transmitted to final consumers depends on the capacity of each market actor to pass-on price changes to their respective clients. The ability of each actor to fix prices, which is a reflection of their market power, in-turn depends on the structure of the markets and of the distribution chains. For example, producers will tend to partially absorb price shock to avoid losing market shares if wholesalers are in a dominant position. Conversely, price shocks will be more widely transmitted to wholesalers if the market structure is more competitive. In the latter case, producers may even tend to pass-on more completely price rises than price decreases. The existence of asymmetries in the price transmission process and their empirical implications are discussed in detail in Vavra and Goodwin (2005). The final transmission to consumers is the result of these complex market relationships at each level of the chain.

\subsection{Transport and Transaction Costs}

Costs incurred to ship imported commodities within the country's borders have to be distinguished from those incurred to distribute commodities, domestically produced or not, to domestic consumption hubs. The former negatively affect the demand for imports and tends to weaken the correlation between domestic and international prices. Regarding the latter, the final impact is less clear-cut: on the one hand, high domestic transport costs or, similarly, the lack of appropriate transport infrastructures, limits the ability of market intermediaries to ship at reasonable costs domestically produced commodities to the main consumption hubs. If production areas are close to the main consumption hubs and the latter are situated far from the country borders, domestic products might be favoured with respect to imported commodities. If the consumption centres are situated close to where imported goods arrive, the effect might be opposite. Import parity prices (benchmark prices plus access cost tariff) are a key determinant of import demand. Its link to international reference prices may be loosened by the existence of high and variable transport and transaction costs.

Transport and transaction costs incurred to import, market and distribute food commodities are often cited as one of the main sources of non-linearities in the price transmission process (Conforti, 2004). Sharp adjustments in market conditions may be triggered by a rise or fall in the 
international price of a given commodity beyond the limits within which it had been evolving since then. For example, if commodities on international markets trade significantly and persistently above domestic prices in a given country, importers might scale back their demand and/or be pushed to change the geographical origin of their products. Domestic producers have an incentive to align their prices to international prices and/or to re-orient their production towards exports. These reactions modify the market equilibrium and affect relative prices. The extent of the impact depends on the size of the initial shock or imbalance and on a range of factors related to the structure of the market as well as to policy conditions.

\subsection{Exchange Rates}

Exchange rate fluctuations can absorb or amplify price changes on international markets, as the national currency appreciates or depreciates vis-à-vis the currency in which the commodities are traded.

\subsection{Policy Interventions}

Policy interventions affect the degree of correlation between international market prices and domestic consumers prices. An extensive list of these instruments, along with a detailed description, has been prepared in the framework of a FAO-led project on the Monitoring of African and Agricultural Policies (MAFAP) .The main policy interventions relevant for price transmission analysis are listed and shortly described below.

Import tariffs: By reducing the relative price competitiveness of foreign goods, they contribute to shelter domestic producers from foreign competition. Higher import tariffs translate into lower price transmission to the extent that tariffs reduce import demand.

Export tariffs: Their objective is generally to ensure that domestic producers sell a higher or minimal share of their products on domestic markets. Export tariffs may be temporarily raised to reduce tensions on domestic prices in situations where prices on international markets are considered as too high. Several countries adopted this approach during the 2007-2008 food price crisis. These policies may lead to adverse effects because they contribute to increase the uncertainty in global supply, especially if the country is a significant player in the market, and may in fact contribute to exacerbate price tensions.

Input subsidies: They can take different forms, including direct subsidies based on the amounts of inputs purchased by the farm, tax deductions, subsidies based on quantities produced or area harvested, etc. Their objective is to support the price competitiveness of domestic products on domestic and international markets by reducing production costs and allowing farmers to sell their products at a lower price than they would otherwise need to in a competitive environment. Similarly to import tariffs, all things being held equal, they contribute to increase the relative price of imported products, reduce import demand and, therefore, potential price transmission between international and domestic prices.

Production subsidies Subsidies based on quantities produced, area harvested, total land area, etc. affect the net revenue of the farm and therefore have similar impacts on import demand and price transmission than input subsidies.

\section{Measuring Price Transmission}

\subsection{Succinct Overview of the Recent Literature}

There is a wide body of literature on the pass-through of international prices to domestic prices for individual commodities and countries. Rapsomanikis and Karfakis (2007) study spatial pricing in commodity markets in Tanzania. Ferrucci et al (2010) provide a review of the recent literature on this topic, focusing on EU countries and the USA. Other recent references are Ninot (2010), for Sub-Saharan African countries, and Aguero (2007).

The analysis of the relationship between price fluctuations on international food commodity markets and average food consumer price inflation seems to have been a less popular topic of study. One of the possible reasons for that may be that policy interventions needed to mitigate the impacts of international market shocks on domestic markets are generally implemented at the level of individual commodity markets. However, with prices of agricultural commodities persistently trading at high levels, interest on this topic has been spurred by the concern that the actual pass-through to food consumer price inflation might become significant enough to affect core inflation, through second round effects, as indicated by Jalil and Tamayo Zea (2011).

Among the recent papers on this topic, Hyeon-seung Huh et al (2012), looked into the transmission of food prices and volatilities using a panel analysis for a set of countries in the Asia-Pacific region. Their analysis, based on a vector auto-regressive (VAR) framework, allows to distinguish the impact of regional price shocks (measured by regional food inflation rates) from shocks on international markets (measured by the FAO Food Price Index). One of the main findings of the study is that domestic food prices react essentially to regional price shocks, while world price shocks contribute virtually none to explaining the variation in price. This result has to be nuanced by the fact that the authors use two different indicators to measure prices at the world and regional levels: a composite price index for a set of commodities traded on international markets is used for world prices while regional prices are a simple average of country Consumer Price Indices (CPIs), which are by construction more closely correlated to country CPIs. A different result might have emerged if a regional commodity price index had been used instead of a regional CPI.

In another recent study, Jalil and Tamayo Zea (2011) provide estimations of transmission elasticities between international commodity prices, food inflation and core inflation for a set of Latin American countries.Vector error 
correction models (VECM) are used to describe the dynamics of: an international food price index (the FAO Food Price Index is used as a benchmark), an activity variable (GDP), food consumer prices (Food CPI), a core inflation index and monetary variables (central bank reference interest rate, exchange rates). The authors find that in almost all the countries of their sample local food prices react in a limited way to shocks in international food prices and that these responses differ significantly across countries both in amplitude (highest response to a unit shock ranging from 0.06 to 0.17 ) and timing (one to six quarters).

Ferrucci et al (2010) measure the response of the Harmonized Food Consumer Price Index (HICP) in the euro area to shocks in international commodity prices. Several deviations from the linear model are tested, among which asymmetric price transmission. The authors find incomplete pass-through in all cases, with the cumulated impact after 6 quarters ranging between $30 \%$ and $50 \%$ depending on the models tested. The highest transmission is found for diary products (0.6) and the lowest for sugar (0.02).

\subsection{Econometric Strategies to Estimate Price Transmission}

Estimation of price transmission equations: The first step in measuring price transmission consists in defining an estimable functional relationship linking regional food consumer prices to international commodity prices. As in any time-series econometric analysis, care has to be taken to ensure that the variables included in the analysis are stationary, i.e. that they do not display any kind of trend. Indeed, the coefficients of the regression between non-stationary (or integrated) time-series may reflect the common trends and not the true underlying correlation between the two variables. This problem of "spurious" regression has been well described in the literature, especially by Granger and Newbold (1973). Several techniques exist to detect non-stationarity, such as the well-known Dickey-Fuller and Phillips-Perron tests for unit roots. In the presence of non-stationarity, which is a characteristic shared by many macroeconomic time-series, it is necessary to de-trend the variables, for example by working on the first-differences or growth rates of the series, and to incorporate them in an appropriate econometric framework, such as autoregressive models (AR) or Error-Correction Models (ECM). These models are shortly described and discussed here in the context of price transmission.

Let $P_{t}$ be the regional food consumer price index for a given country measured in $t, P_{t}^{*}$ a composite international commodity price index, such as the FAO Food Price Index, $X_{t}$ a set of explanatory variables (GDP, agricultural production, food import dependency ratio, exchange rate, etc.) assumed to be exogenous and $\varepsilon_{t}$ a random error term. Variables in low-cases represent natural logarithms, and growth rates or first log-differences when dotted. Vectors are in bold.

Augmented Auto-Regressive (AR): Food inflation transmission is estimated by regressing changes in food consumer prices on their past and on present and past changes in international prices and in the set of exogenous variables:

$$
\dot{p}_{t}=\mathrm{c}+\sum_{\mathrm{i}=1}^{\mathrm{p}} \alpha_{\mathrm{i}} \dot{p}_{t-i}+\sum_{\mathrm{j}=0}^{\mathrm{k}} \beta_{\mathrm{j}} \dot{p}_{t-j}^{*}+\sum_{\mathrm{l}=0}^{\mathrm{m}} \gamma_{\mathrm{l}} \dot{x}_{t-l}+\varepsilon_{t}
$$

Error Correction Models (ECM): This approach is appropriate to model a set of co-integrated series ${ }^{1}$ if the time span is large enough to capture short and long-term dynamics and if the main explanatory variables can be included in the model. The lagged residual from the co-integrating relationship (which represents the long-term or equilibrium relationship) is added to the auto-regressive component. When food prices are above (under) their estimated long-term level, a proportion of this gap is subtracted (added) to the short-term dynamics in the following period, bringing the estimation closer to its long-term or equilibrium path. $\mu$ measures the speed at which the endogenous variable, food consumer prices, converges towards its long-term path after a shock:

$$
\begin{aligned}
\dot{p}_{t}=\mathrm{c}+ & \sum_{\mathrm{i}=1}^{\mathrm{p}} \alpha_{\mathrm{i}} \dot{p}_{t-i}+\sum_{\mathrm{j}=0}^{\mathrm{k}} \beta_{\mathrm{j}} \dot{p}_{t-j}^{*}+\sum_{\mathrm{l}=0}^{\mathrm{m}} \boldsymbol{\gamma}_{\mathrm{l}} \dot{\boldsymbol{x}}_{t-l} \\
& +\mu\left[p_{t-1}-\left(\mathrm{a}+\beta p_{t-1}^{*}+\boldsymbol{\gamma} \boldsymbol{x}_{t-1}\right)\right]+\varepsilon_{t}
\end{aligned}
$$

Non-Linear ARs or ECMs: These models may be sophisticated by the introduction of non-linearities, which in the context of price transmission are mainly of two sorts: threshold effects and asymmetric transmission. Threshold models may be used to account for the fact that the nature of the relationship linking $P_{t}$ to $P_{t}^{*}$ may evolve over time: for example, price dynamics in periods of high volatility may differ from those prevailing when volatility is lower; the introduction of new regulations, policies, etc. may also durably modify the nature of the relationship linking macroeconomic time series such as food consumer prices and international commodity prices (structural breaks); the existence of transport and transaction costs, as previously explained, contribute to create and amplify threshold effects. Different models can be used depending on the nature of the threshold: existence or not of a structural break, extent of the knowledge on the underlying mechanism governing the change in the nature of the relationship (e.g. price volatility level), timing of the change (brutal or smooth/continuous). An example is given below for an AR model with a structural break in the relationship at an unknown date $\bar{t}$ :

1 Two time series are said to be co-integrated to the order $p, \mathrm{CI}(p)$, if each of them is integrated to the degree $p, \mathrm{I}(p)$, and if some linear combination of these series is integrated to the order $p-1$. It follows that if two time-series are $\mathrm{I}(1)$ and if some linear combination is stationary, i.e. $\mathrm{I}(0)$, the two time-series are said to be co-integrated and can be modelled using an ECM. 


$$
\begin{aligned}
& \dot{p}_{t}=\delta(\mathrm{t} \leq \bar{t}) \cdot \mathrm{AR}_{1}\left(\dot{p}, \dot{p}^{*}, \dot{\boldsymbol{x}}\right) \\
& \quad+(1-\delta(\mathrm{t} \leq \bar{t})) \cdot \mathrm{AR}_{2}\left(\dot{p}, \dot{p}^{*}, \dot{\boldsymbol{x}}\right)
\end{aligned}
$$

Where $\delta(\mathrm{t} \leq \bar{t})=1 \quad$ if $\mathrm{t} \leq \bar{t}$ and $\delta(\mathrm{t} \leq \bar{t})=0$ otherwise and where $\operatorname{AR}_{1}($.$) and \operatorname{AR}_{2}($.$) are linear$ functions of the past of $\dot{p}$ and present and past of $\dot{p}^{*}$ and $\dot{\boldsymbol{x}}$.

Another type of non-linearity arises when positive price shocks on international markets are not passed on to consumer prices in a similar way than negative ones. To account for the possibility of asymmetries in the price transmission process, the rule governing the shift from one transmission process to the other has to be based on observed values of $\dot{p}_{\mathrm{t}}^{*}$ :

$$
\begin{aligned}
\dot{p}_{t} & =\delta\left(\dot{p}^{*}{ }_{\mathrm{t}} \leq 0\right) \cdot \mathrm{AR}_{1}\left(\dot{p}, \dot{p}^{*}, \dot{\boldsymbol{x}}\right) \\
& +\left(1-\delta\left(\dot{p}^{*}{ }_{\mathrm{t}} \leq 0\right)\right) \cdot \operatorname{AR}_{2}\left(\dot{p}, \dot{p}^{*}, \dot{\boldsymbol{x}}\right)
\end{aligned}
$$

Vector ARs or ECMs: When the causality between explained and explanatory variables goes in both directions, a multi-dimensional version of these models can be used, where each variable is considered in the model as both endogenous and exogenous. As an example, a bivariate AR for $\dot{p}$ and $\dot{p}^{*}$ is defined by:

$$
\left(\begin{array}{c}
\dot{p} \\
\dot{p}^{*}
\end{array}\right)_{t}=\mathbf{c}+\sum_{\mathrm{i}=1}^{\mathrm{p}} \mathbf{A}_{\mathrm{i}}\left(\begin{array}{l}
\dot{p} \\
\dot{p}^{*}
\end{array}\right)_{t-i}+\sum_{\mathrm{l}=0}^{\mathrm{m}} \mathbf{B}_{1} \dot{x}_{t-l}+\varepsilon_{t}
$$

Where $\mathbf{c}=\left(\begin{array}{c}\mathrm{c} \\ \mathrm{c}^{*}\end{array}\right), \quad \mathbf{A}_{\mathrm{i}}=\left(\begin{array}{cc}\alpha_{\mathrm{i}} & \beta_{\mathrm{i}} \\ \alpha_{\mathrm{i}}^{*} & \beta_{\mathrm{i}}^{*}\end{array}\right), \quad \mathbf{B}_{1}=\left(\begin{array}{l}\boldsymbol{\gamma}_{1} \\ \boldsymbol{\gamma}_{1}^{*}\end{array}\right)$ and $\varepsilon_{t}=\left(\begin{array}{c}\varepsilon \\ \varepsilon^{*}\end{array}\right)$, the coefficients with a star are those of the regression of $\dot{p}^{*}$ on $\dot{p}$.

Measuring price transmission using Impulse Response Functions: Food price inflation transmission is defined in this paper as the percentage change in food consumer prices resulting from a given change in the international market price of a basket of agricultural commodities, everything else being held equal. Concretely, our objective is to quantify the impact of a transitory shock of magnitude $s$ in international food prices occurring in t, i.e. $\dot{p}^{*}{ }_{\mathrm{t}}=s$, on food consumer prices in $\mathrm{t}, \mathrm{t}+1, \ldots, \mathrm{t}+h, \ldots, \mathrm{t}+\mathrm{H}$. Impulse Response Functions (IRF) can be used to respond to this question. IRF are used in dynamic systems to determine the magnitude and time-distribution of the response of the endogenous variable to a shock in one of the explanatory variables. Mathematically, for a given shock $s$ occurring in $\mathrm{t}$, the IRF of $\dot{p}$ with respect to $\dot{p}^{*}$ in $t+h$ can be defined as:

$$
\operatorname{IRF}(h)=\left.\frac{\partial \dot{p}_{t+h}}{\partial \dot{p}^{*}{ }_{\mathrm{t}}}\right|_{\dot{p}_{\mathrm{t}}=\mathrm{s}}
$$

Cumulated IRF measure the accrued impact from the time of the shock up to a given point in time:

$$
I R F_{\text {cum }}(H)=\sum_{\mathrm{h}=0}^{\mathrm{H}} \operatorname{IRF}(h)
$$

$I R F_{\text {cum }}(0)=\operatorname{IRF}(0)$ is the contemporaneous impact of the shock and $\lim _{H \rightarrow \infty} I R F_{\text {cum }}(H)$ the long-term or total impact. When using an ECM, the cumulated IRF have the property to converge towards the long-run elasticity $\beta$ (Johansen, 2004).

Price transmission can be approached by a set of measures, among which: the maximum impact of the shock and its associate timing, the short-term impact, the long-run impact and the time it takes for the shock to reach its full impact (response horizon). These dimensions of price transmission can all be measured using IRF. Lütkepol and Reimers (1992) and Johansen (2004) provide more details on IRF, with a specific focus on their use in ECM.

\subsection{Our approach}

The objective of this paper is to estimate the transmission of price fluctuations from international markets to consumers, for different regions of the world. The data used and the estimation strategy adopted are shortly described in this section.

Data: In this study, monthly data has been used to appropriately capture market shocks which, by essence, tend to occur at a high frequency - weekly or even daily - as it is the case on markets where commodities or products are traded on a daily basis. If quarterly or annual data had been used instead, shocks might have been smoothed and therefore less adequately reflected by the data. The use of monthly data compared to quarterly or annual data also allows to significantly increase the sample size from which the estimations are drawn (157 months) and therefore potentially improve the precision and accuracy of the estimates. However, using monthly data reduces the possibility to include auxiliary variables in the model, such as regional GDP estimates or other macroeconomic variables, as many of them are not available at this frequency.

Two types of price series are used in this analysis: international market prices for agricultural commodities and average prices for food consumer items measured in different regions. The FAO Food Price Index (FPI) provides a measure of the monthly change in international prices of a basket of food commodities. It consists of the average of five commodity group price indices (representing 55 quotations), weighted with the average export shares of each of the groups for 2002-2004 ${ }^{2}$.

Average food consumer prices at regional level are represented by FAO's Global and Regional Food Consumer Price Indices (CPIs) ${ }^{3}$. The aggregation procedure is based on the use of population weights to better reflect regional food inflation and its impacts on households. Not all regions have been included in the estimations, but only those which can be considered as relatively homogeneous with respect to the characteristics of their respective agricultural markets. For example, Europe has been included as one region but,

2 For more details on FAO's FPI and other commodity price indices: http://www.fao.org/worldfoodsituation/foodpricesindex/en/ 3 For more details on FAO's Global and Regional Food CPIs: http://www.fao.org/economic/ess/ess-economic/cpi/en/ 
within Latin America, South America and Central America have been distinguished. Certain regions have been excluded because of a lack of data (Middle Africa, Central Asia). Eastern Asia has not been considered in the analysis because of the high degree of heterogeneity among its countries (high growth and inflation in China, low inflation or deflation in Japan) and because of the importance of internal country drivers in determining price trends.

Figure 2, which compares fluctuations in the Global Food CPI with changes in the FAO Food Price Index, tends to indicate that, since 2002, both series have moved in the same general direction, with the food CPI lagging behind fluctuations in the FPI. This is particularly noticeable for peaks and troughs, such as during the food price crisis of 2007-08, when the FPI rose sharply, with the global food CPI following the increase a few months later. It is also clear from the chart on the left-hand side, in which both series are plotted using the same scale, that volatility in the FPI is not fully transmitted to the global food CPI. Although significant differences exist between regions, the same general pattern can be observed. Annex 1 provides charts for each region included in this analysis.

Estimation strategy: Separate univariate ECM have been estimated for each of the regions investigated. The use of vector ECM, where international market prices and regional consumer prices are both considered endogenous and exogenous, has not been deemed necessary. The main reason for this choice is that the direction of the relationship, from international market prices to consumer's prices, is clear given the two extremes of the value-chain to which these prices refer to. This would not be the case, for example, if the objective was to estimate price transmission between wholesale and retail prices for individual commodities. The use of multi-dimensional models also increases the number of parameters to estimate and reduces the degrees of freedom of the regression (over-parameterization), potentially affecting the accuracy and precision of the final estimates. For example, in a VAR with only 3 variables and 2 lags, 18 parameters have to be estimated.

Linear ECM has been estimated in this analysis. Further research is needed to account for nonlinearities in the estimation of transmission elasticities. As a prelude to such analysis, possible structural breaks were identified by implementing sequential Chow tests over 2007-2008, corresponding to the period during which the food price crisis occurred. The date of the structural break was defined as the one for which the null hypothesis of linearity of the relationship was rejected with the highest degree of confidence. Further research on this topic should be directed at better identifying threshold effects, for example using rules to identify regime shifts (e.g. price volatility levels), and at finding ways to incorporate them appropriately in the modeling framework, such as allowing for smooth transition between regimes.

IRF and cumulated IRF were calculated on the basis of model simulations with normal residuals. Empirical quantiles and standard error estimates resulting from these simulations were used to determine $95 \%$-confidence bands for the IRFs. This and other approaches to determine confidence bands for IRF are discussed in Griffiths and Lütkepol (1990). These simulations were generally based on 100 draws, as this number has been found to provide sufficient robustness in the estimates. For a couple of regions with more unstable estimates, this number has been increased to 150 .

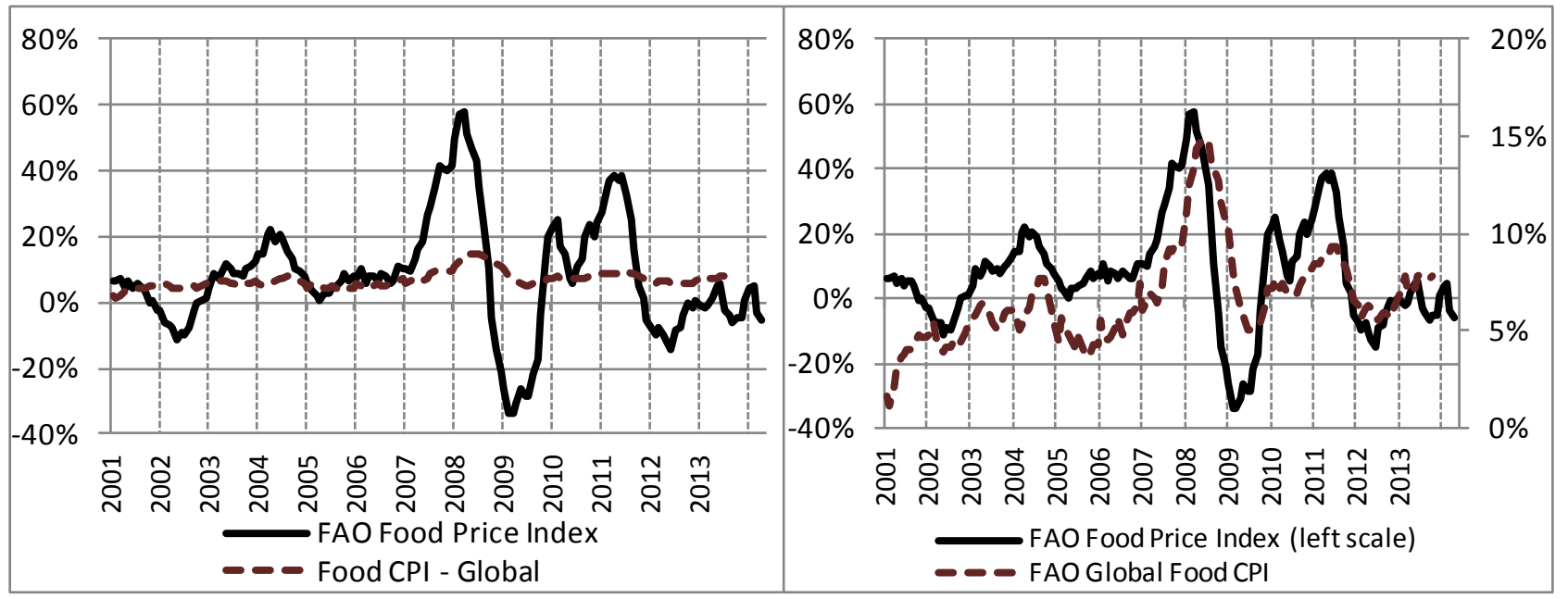

Source: FAO and International Labour Organization (country food CPIs)

Figure 2. Global food consumer prices and international commodity prices (year-over-year) 


\section{Results: Overview of Price Transmission Estimates}

The empirical results confirm that the transmission of price changes from international markets to consumers is lagged and incomplete, with significant differences between regions. Table 1 provides a synthesis of the results and Annex 2 presents charts of the impulse response functions and their respective confidence bands. Detailed region-specific estimation results and statistics are provided in Table 2.

The time it takes for the impact to reach its maximum is longer in developed economies such as North America and Europe, where it is attained in the $8^{\text {th }}$ and $11^{\text {th }}$ month respectively. In developing regions, the maximum impact is generally felt sooner after the initial shock, often in the $1^{\text {st }}$ or $2^{\text {nd }}$ month. The highest impact is also greater in developing regions, where it reach 0.05 (Eastern Africa), compared to 0.01 in North America and Europe.

The cumulated impacts are also in line with this pattern: 32 months after the initial shock, approximately $20 \%$ of the initial rise in international prices had been passed on to consumers in North America and Europe, $12-20 \%$ in Latin America, $20 \%$ and $38 \%$ respectively in South Asia and South-Eastern Asia and $25-80 \%$ in Africa. Long-run elasticities are also significantly higher in developing regions: between 0.5 and 1 in Africa, close to 0.5 in Latin America and 0.3 in North America and Europe. Ferrucci et al. (2010) find a similar long-run elasticity of 0.3 for the euro area, using a different measure of international food prices. This elasticity was found to be significantly higher $(0.5)$ in the model allowing for asymmetries. The comparatively high transmission elasticities in Eastern and Southern Africa are consistent with Rapsomanikis (2009), who found strong transmission for maize, the main staple food for the countries of the region.

The regional differences in the timing and size of the impacts tends to confirm the importance of value-chains in delaying and absorbing upstream market shocks. Developed economies, in which households tend to spend a higher share of their income on processed products than consumers in developing countries, are characterized by more extended value-chains. Price transmission is generally slower and lower in these markets, as price shocks are absorbed and delayed by the multiple market actors that process, package, ship and distribute products (see Section 2 for more details).

As noted before, the relative size of the impact also crucially depends on the share of imports in domestic demand (import dependency ratio), which is positively correlated to price transmission. On average, countries in North America, Europe and Latin America tend to be less reliant on imports than countries in Africa, where price transmission has been found to be higher and faster. While this result may be valid at regional level, it cannot be directly extrapolated to individual countries given the significant differences existing even within sub-regions. For example, while many small central American countries are characterized by relatively high import dependency ratios (often higher than $30 \%$, reaching $50 \%$ in the case of Costa Rica), it is less the case of Mexico, the main country of the region. The relatively low estimated transmission for Central America may therefore essentially reflect transmission patterns in Mexico, a country with a developed agricultural sector and less reliant on food imports than its southern neighbors. Evidence of a slow and low pass-through in Mexico is provided by Jalil and Tamayo Zea (2011).

Table 1. Response of regional food consumer prices to a $1 \%$ shock in the FAO Food Price Index

\begin{tabular}{|c|c|c|c|c|c|c|c|c|c|c|c|}
\hline & & $\begin{array}{c}\text { North } \\
\text { America }\end{array}$ & Europe & $\begin{array}{c}\text { South } \\
\text { America }\end{array}$ & $\begin{array}{c}\text { Central } \\
\text { America }\end{array}$ & $\begin{array}{c}\text { South- } \\
\text { Eastern } \\
\text { Asia } \\
\end{array}$ & $\begin{array}{c}\text { Southern } \\
\text { Asia }\end{array}$ & $\begin{array}{l}\text { North } \\
\text { Africa }\end{array}$ & $\begin{array}{c}\text { Western } \\
\text { Africa }\end{array}$ & $\begin{array}{c}\text { Eastern } \\
\text { Africa }\end{array}$ & $\begin{array}{c}\text { Southern } \\
\text { Africa }\end{array}$ \\
\hline \multicolumn{2}{|c|}{ Highest effect (\%) } & 0.01 & 0.01 & 0.02 & 0.01 & 0.02 & 0.02 & 0.01 & 0.03 & 0.05 & 0.03 \\
\hline \multicolumn{2}{|c|}{$\begin{array}{c}\text { Horizon at which } \\
\text { highest effect occurs } \\
\text { (month) }\end{array}$} & 8 & 11 & 1 & 2 & 2 & 1 & 7 & 7 & 2 & 13 \\
\hline \multirow{6}{*}{$\begin{array}{c}\text { Response } \\
(\%) \\
\text { after: }\end{array}$} & 2 months & 0.01 & 0.01 & 0.03 & 0.01 & 0.02 & 0.03 & 0.01 & 0.03 & 0.05 & 0.0 \\
\hline & 4 months & 0.03 & 0.02 & 0.05 & 0.04 & 0.04 & 0.04 & 0.03 & 0.06 & 0.11 & 0.02 \\
\hline & 8 months & 0.07 & 0.06 & 0.08 & 0.07 & 0.10 & 0.06 & 0.07 & 0.16 & 0.21 & 0.10 \\
\hline & 16 months & 0.14 & 0.13 & 0.11 & 0.12 & 0.21 & 0.08 & 0.13 & 0.33 & 0.47 & 0.28 \\
\hline & 32 months & 0.22 & 0.19 & 0.12 & 0.20 & 0.38 & 0.20 & 0.25 & 0.60 & 0.79 & 0.54 \\
\hline & Long-term & 0.30 & 0.27 & 0.42 & 0.47 & 0.57 & 0.54 & 0.53 & 0.90 & 1.05 & 0.64 \\
\hline
\end{tabular}

Source: author's calculations

Note: the highest effect corresponds to the highest IRF which did not include 0 in its $95 \%$ confidence interval; the responses for each horizon ( 2 months, 4 months, etc.) correspond to the sum up to the given horizon of the IRF which did not include 0 in their confidence interval; the long-term elasticity is the sum of all the IRF statistically different than 0 at the $95 \%$ threshold. 
Table 2. Statistics on the estimated error-correction models

\begin{tabular}{|c|c|c|c|c|c|c|c|c|c|c|}
\hline & $\begin{array}{c}\text { North } \\
\text { America }\end{array}$ & Europe & $\begin{array}{c}\text { South } \\
\text { America }\end{array}$ & $\begin{array}{c}\text { Central } \\
\text { America }\end{array}$ & $\begin{array}{c}\text { South-Eastern } \\
\text { Asia }\end{array}$ & $\begin{array}{c}\text { Southern } \\
\text { Asia }\end{array}$ & $\begin{array}{c}\text { North } \\
\text { Africa }\end{array}$ & $\begin{array}{c}\text { Western } \\
\text { Africa }\end{array}$ & $\begin{array}{c}\text { Eastern } \\
\text { Africa }\end{array}$ & $\begin{array}{c}\text { Southern } \\
\text { Africa }\end{array}$ \\
\hline $\boldsymbol{\beta}$ & 0.30 & 0.28 & 0.85 & 0.63 & 0.84 & 0.78 & 0.84 & 0.95 & 1.34 & 0.79 \\
\hline $\boldsymbol{\mu}$ & -0.03 & -0.03 & -0.005 & -0.03 & -0.02 & -0.02 & -0.01 & -0.05 & -0.02 & -0.02 \\
\hline $\begin{array}{c}\text { Augmented } \\
\text { DF Test } \\
\text { (p-value) }\end{array}$ & 0.01 & 0.06 & 0.09 & 0.02 & $<0.01$ & 0.28 & 0.20 & 0.01 & 0.01 & 0.05 \\
\hline Adjusted $\boldsymbol{R}^{2}$ & $39 \%$ & $34 \%$ & $45 \%$ & $17 \%$ & $14 \%$ & $28 \%$ & $18 \%$ & $23 \%$ & $35 \%$ & $47 \%$ \\
\hline $\begin{array}{c}\text { Existence of a } \\
\text { structural } \\
\text { break }\end{array}$ & $\begin{array}{c}\text { Yes } \\
\text { (March } \\
2008)\end{array}$ & No & No & No & $\begin{array}{c}\text { Yes (Nov. } \\
2008)\end{array}$ & $\begin{array}{c}\text { Yes (Jan. } \\
2008)\end{array}$ & No & No & No & No \\
\hline
\end{tabular}

Note: The null hypothesis associated with the augmented DF test is the presence of a unit root (i.e. non-stationarity). A p-value of 0.1 means that the null hypothesis of non-stationarity can be rejected with a risk of $10 \%$

\section{Conclusions}

This paper presented measures of the transmission of international commodity prices to food consumer prices in several regions of the world. The results are in line with the findings of previous studies, i.e. that transmission is generally incomplete and lagged. It also provides new evidence of differences in speed and extent of transmission among regions. Africa is the region with the highest transmission, especially Eastern Africa, where $5 \%$ of the initial shock is passed-on to consumer prices after only 2 months and $20 \%$ after 8 months. The lowest transmission is found in North America and Europe, where close to $30 \%$ of the initial impact is passed on to consumer prices. Asia (South and South-East) and Latin America are in an intermediate situation with on the long-run around half of the shock transmitted to consumer prices.

These results are preliminary and further research is needed to improve the estimates. First, additional explanatory factors, such as activity data, import dependency ratios and exchange rates need to be incorporated in the estimation framework. Second, assymetries and other non-linearities need to be taken into account, as several studies have demonstrated their importance in the estimation of price relationships. Third, the measure of international food prices used for the estimations does not necessarily adequatly reflect regional import and consumption patterns: the FAO Food Price Indexes are weighted by average export shares and may therefore not appropriately capture trends in regional food import prices. A re-weighting of individual commodity prices by the appropriate import shares might therefore be needed to obtain indices more representative of regional patterns. Finally, the estimation framework could be improved to accommodate correlations between regional-level price shocks. To this end, the adoption of a multi-dimensional framework (VAR, VECM) or the implemention of SURE regressions (seemingly unrelated regression equations) might be useful.

\section{Annexes}

a Food consumer prices and international commodity prices (year-over-year changes)

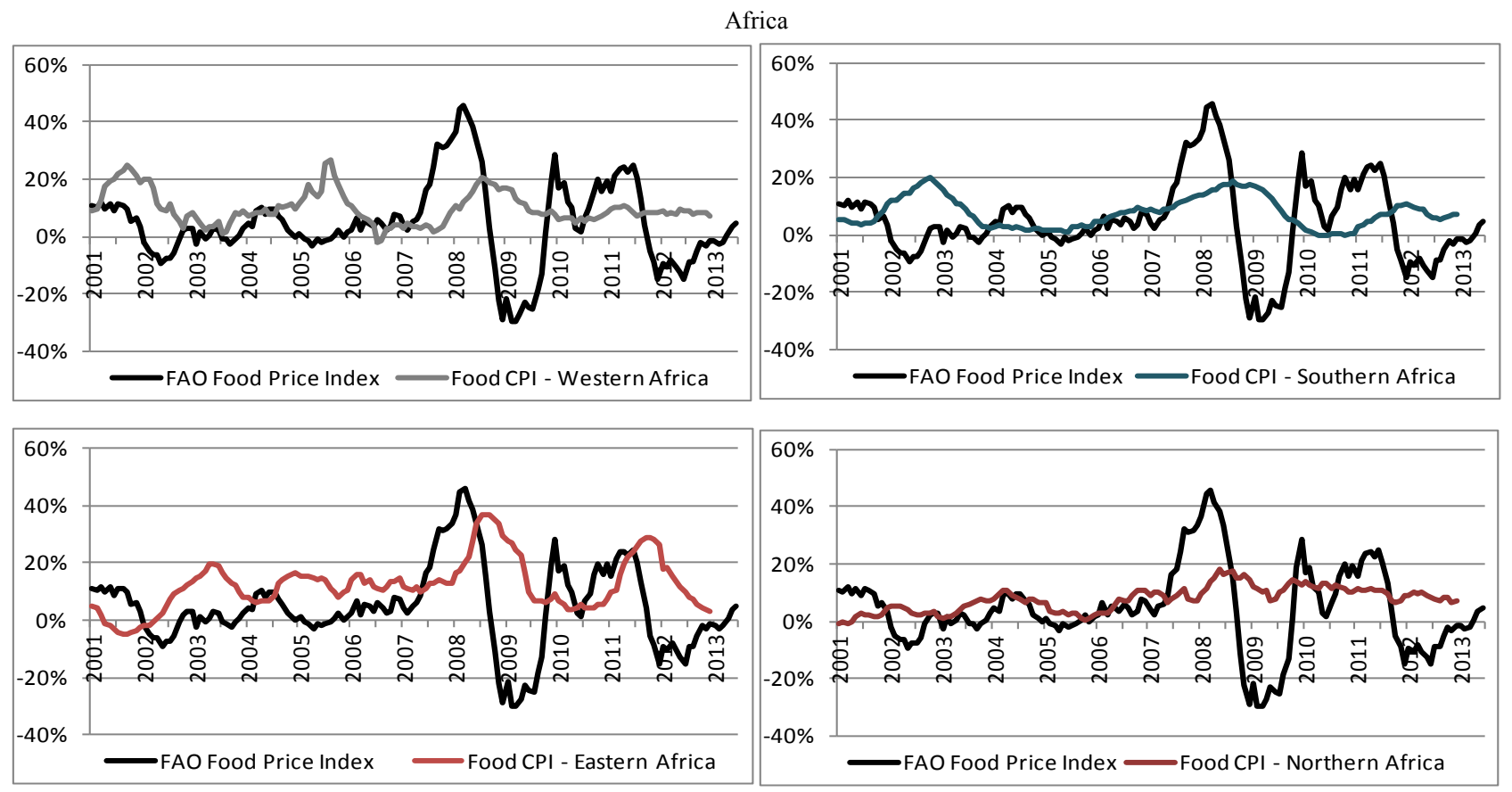


Latin America
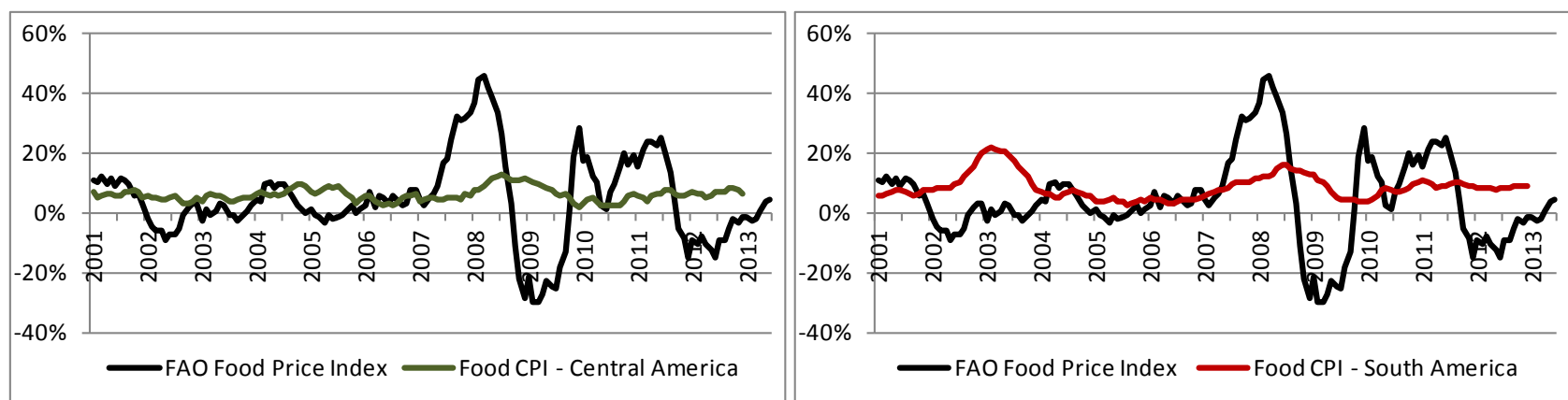

Asia
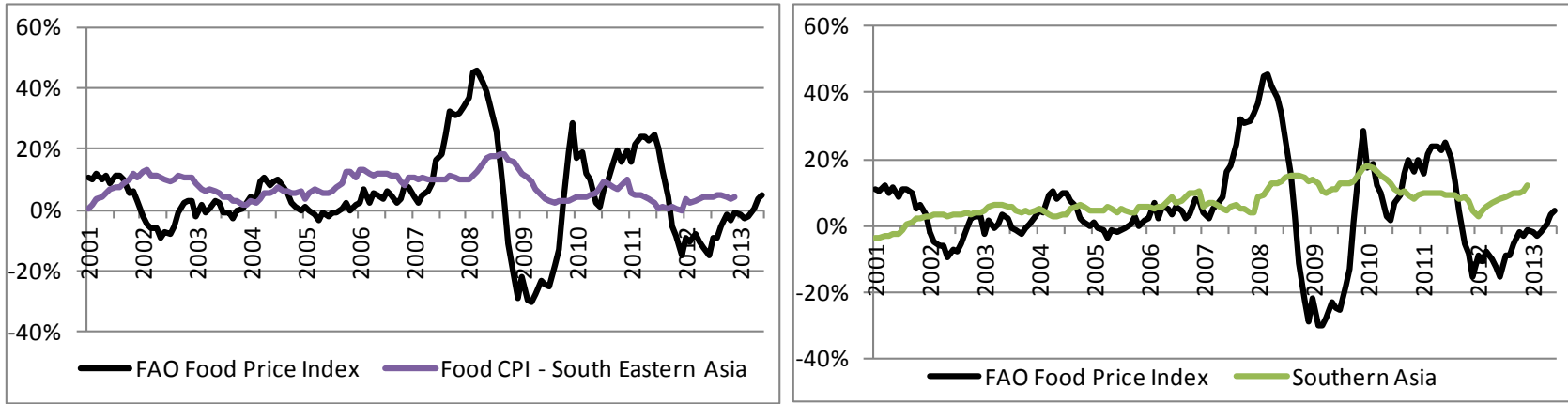

Europe and North America
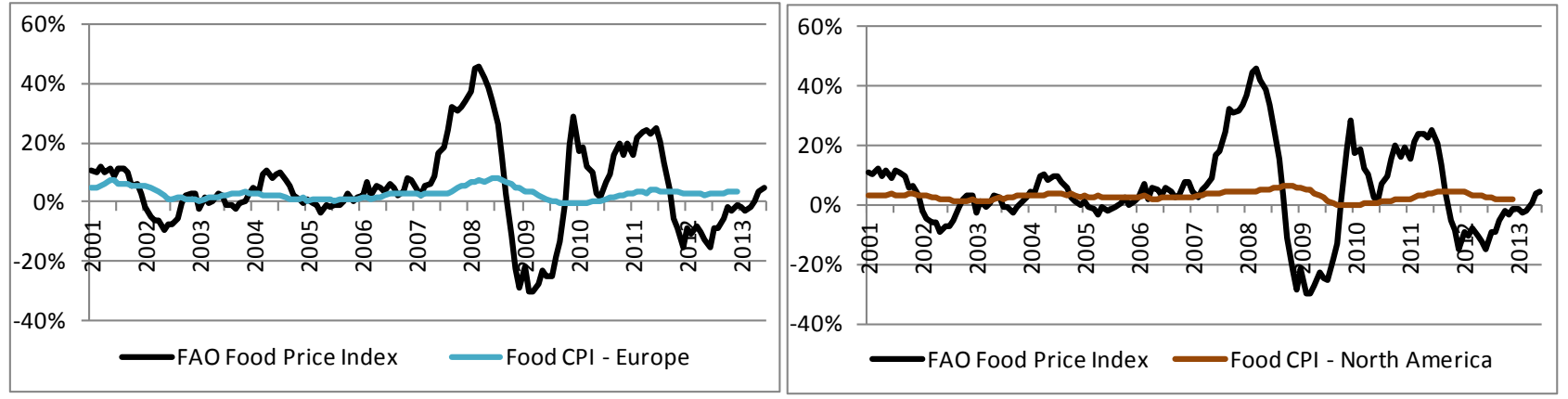

\section{b}

\section{Impulse response functions}

The impulse response functions presented here measure the response of regional food consumer prices (FAO Food CPIs) to a unit shock in international food prices (FAO Food Price Index). The impulse response functions and their respective $95 \%$ confidence bands have been determined by model simulations ( $\mathrm{N}=100$ draws) based on normal residuals. 
Africa
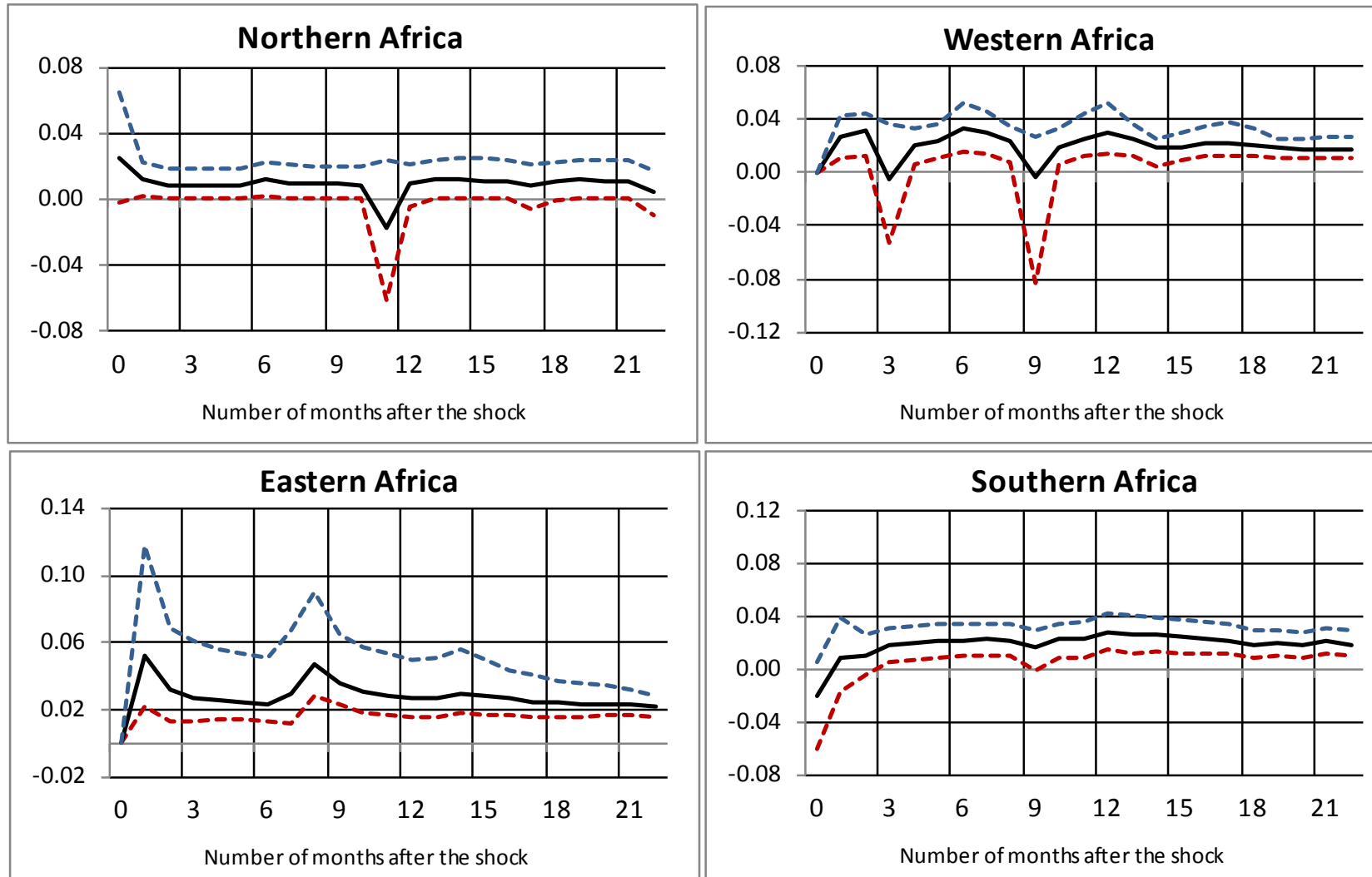

Latin America
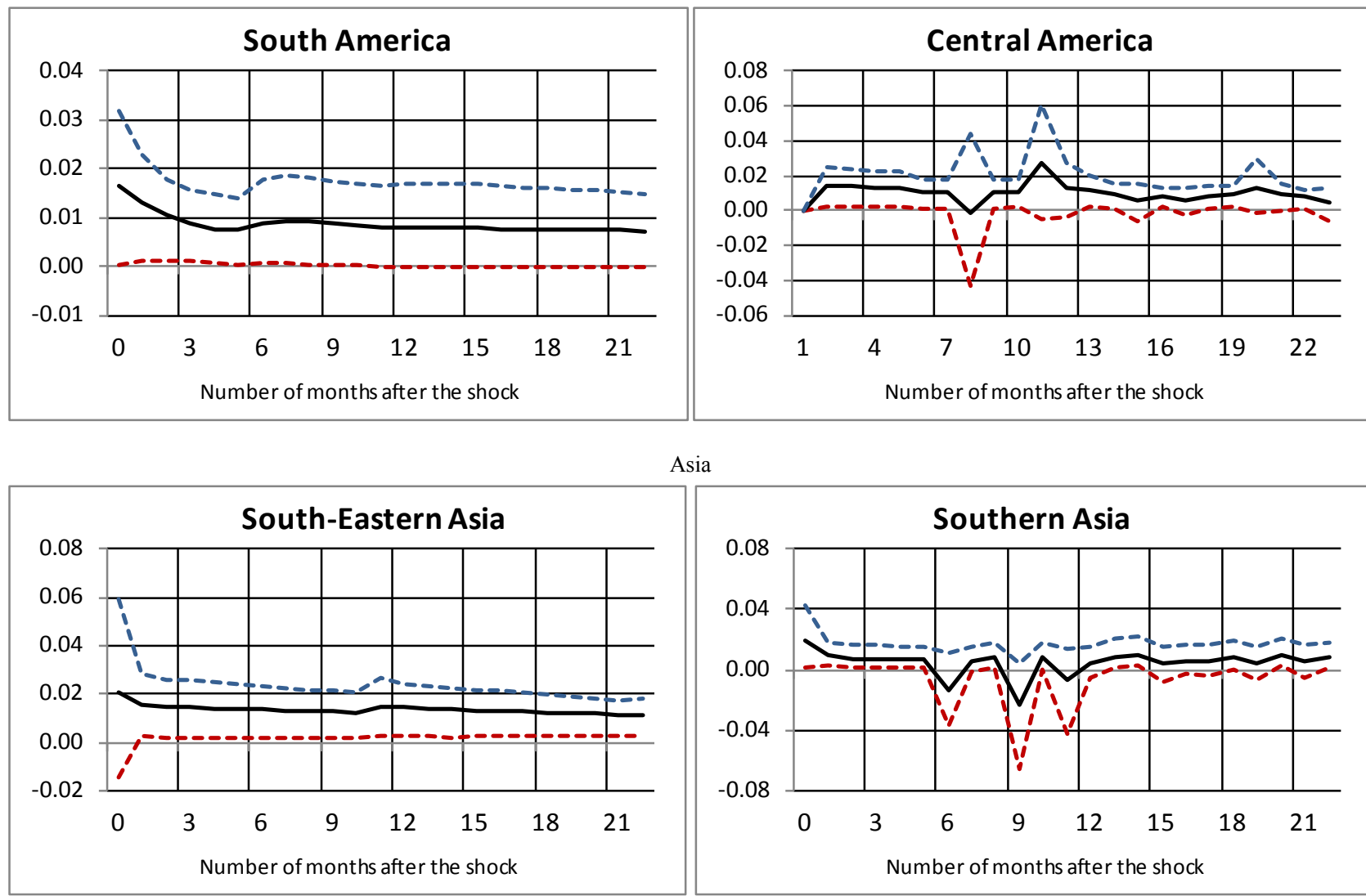
Europe and North America

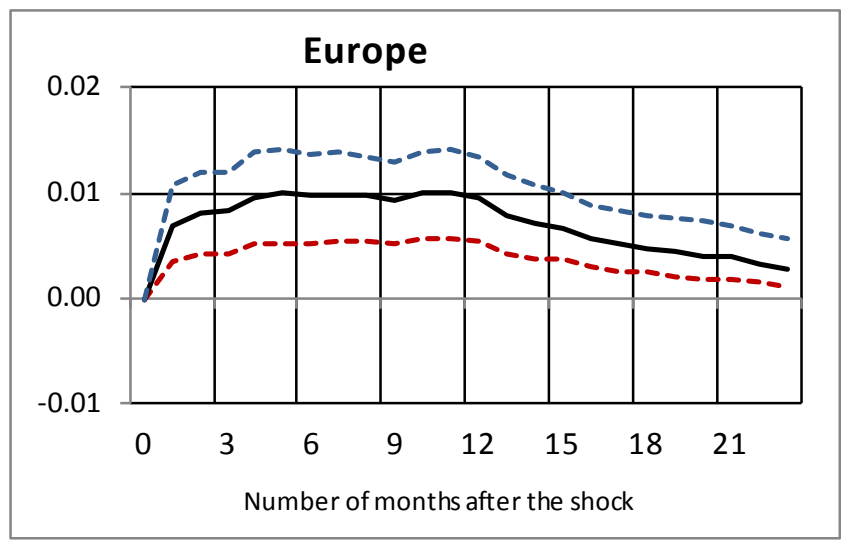

\section{c}

\section{Regions and country coverage}

Northern America: United States of America, Canada, Bermuda

Central America: Costa Rica, El Salvador, Guatemala, Honduras, Mexico, Nicaragua, Panama

South America: Argentina, Bolivia, Brazil, Chile, Colombia, Ecuador, Paraguay, Peru, suriname, Uruguay, Venezuela

Europe : all EU-27 countries, Albania, Iceland, Latvia, Norway, Switzerland, Island of Man, Republic of Moldova

South-Eastern Asia: Brunei, Cambodia, Indonesia, Lao, Malaysia, Myanmar, Philippines, Singapore, Thailand

Southern Asia: Bangladesh, India, Iran, Maldives, Nepal, Pakistan, Sri Lanka

Northern Africa: Algeria, Egypt, Morocco, Tunisia

Western Africa: Benin, Burkina Faso, Côte d'Ivoire, Gambia, Ghana, Guinea, Mali, Mauritania, Niger, Nigeria, Senegal, Sierra Leone

Eastern Africa: Ethiopia, Kenya, Madagascar, Malawi, Mauritius, Mozambique, Rwanda, Seychelles, Uganda, Tanzania, Zambia

Southern Africa: Botswana, Lesotho, Namibia, South Africa

\section{REFERENCES}

[1] Conforti, P. 2004. Price transmission in selected agricultural markets, FAO Commodity and Trade Policy Research Working Paper, No. 7.

[2] Ferrucci, G., Jiménez-Rodriguez, R., Onorante, L. 2010. Food Price Pass-Through in the Euro Area: The Role of Asymmetries and Non-Linearities, Working Paper Series of the European Central Bank, No 1168.

[3] Griffiths, W. \& Lütkepohl, H. 1990. Confidence Intervals for Impulse Responses from VAR Models: A Comparison of Asymptotic Theory and Simulation Approaches, Working Paper, University of New England, NSW, Department of

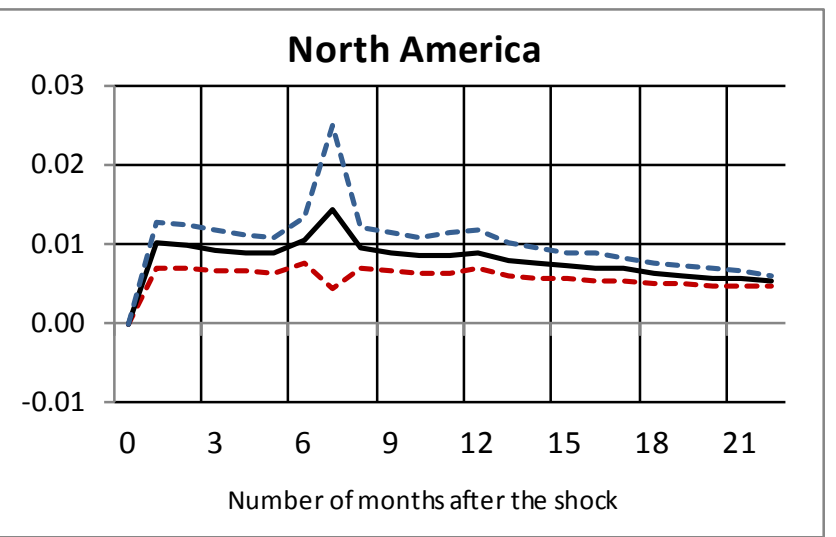

Economics, No. 42.

[4] Huh, H-S. \& Lee, H-H. \& Park, C-Y. 2012. International Transmission of Food Prices and Volatilities, Food Securities in Asia and the Pacific: Issues and Challenges, Background Paper, Asian Development Bank.

[5] Jalil, M. \& Tamayo Zea, E. 2011. Pass-through of International Food Prices to Domestic Inflation During and After the Great Recession: Evidence from a Set of Latin American Economies, Desarrollo y Sociedad, first semester 2011, pp. 135-179.

[6] Johansen, S. 2004. Cointegration: an overview, Working Paper, University of Copenhagen, Department of Applied Mathematics and Statistics.

[7] Lütkepohl, H. \& Reimers, H-E. 1992. Impulse response analysis of cointegrated systems, Journal of Economic Dynamics and Control, Vol. 16, pp. 53-78.

[8] Minot, N. 2010. Transmission of World Food Price Changes to Markets in Sub-Saharan Africa, Report of a Study Funded by the Policy and Research Division of the Department for International Development (DfID) of the United Kingdom.

[9] Karfakis, P. \& Rapsomanikis, G. 2007. Margins across time and space: Threshold Cointegration and Spatial Pricing Applications to Commodity Markets in Tanzania, Paper presented in the Workshop on Staple Food Trade and Market Policy Options for Promoting Development in Eastern and Southern Africa, Rome.

[10] Rapsomanikis, G. 2009. The 2007-2008 food price episodes: Impact of policies in Eastern and Southern Africa, FAO Commodity and Trade Technical Paper.

[11] Rapsomanikis, G., Hallam, D., Conforti, P. 2003. Market Integration and Price Transmission in Selected Cash and Crop Markets of Developing Countries: Review and Applications, Commodity Market Review 2003-2004, FAO.

[12] Uctum, R. 2007. Économétrie des Modèles à changement de régimes: un essai de synthèse, L'Actualité économique, Vol. 83 , No. 4, pp. 447-482.

[13] Vavra, P. \& Goodwin, B. K. 2005. Analysis of Price Transmission along the Food Chain, OECD Food, Agriculture and Fisheries Working Papers, No 3, OECD Publishing. 